\title{
Effects of acetoacetate and D- $\beta$-hydroxybutyrate on bovine in vitro embryo development in serum-free medium
}

\author{
Enrique Gómez ${ }^{\mathrm{a},{ }^{*}}$, Paloma Duque ${ }^{\mathrm{a}}$, Elena Díaz ${ }^{\mathrm{a}, 1}$, Nieves Facal $^{\mathrm{a}}$, \\ Isaac Antolín ${ }^{\mathrm{b}}$, Carlos Hidalgo ${ }^{\mathrm{a}}$, Carmen Díez ${ }^{\mathrm{a}}$

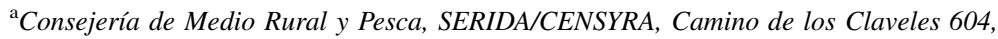 \\ Somió, 33203 Gijón, Asturias, Spain \\ ${ }^{\mathrm{b}}$ Departamento de Morfología y Biología Celular, Universidad de Oviedo, \\ Julián Clavería s/n, 33006 Oviedo, Asturias, Spain
}

Accepted 15 October 2001

\begin{abstract}
It is known that the ketone bodies acetoacetate and D- $\beta$-hydroxybutyrate can be metabolized by the early bovine embryo for in vitro development. In the present work, we report experiments leading to the culture of bovine embryos in the absence of serum. In vitro-produced bovine zygotes were cultured in modified synthetic oviduct fluid medium supplemented with acetoacetate derivatives, acetoacetate and D- $\beta$-hydroxybutyrate. Acetoacetate and its derivatives prevented blastocysts from forming in the absence of serum during the whole culture period. However, from Days 6 to 8 of culture in the absence of serum, acetoacetate did not affect development as compared to controls containing lactate and pyruvate or no substrate. Interestingly, D- $\beta$-hydroxybutyrate stimulated blastocyst and expansion development, and allowed lipid mobilization. In feeder cells coculture, embryos produced with D- $\beta$-hydroxybutyrate showed improved hatching. Embryos cultured in D- $\beta$ hydroxybutyrate were viable upon transfer to recipients, although no pregnancies were confirmed later by ultrasonic scanning. The protective effect of serum upon embryos cultured in medium containing acetoacetate is apparently not required in the presence of D- $\beta$-hydroxybutyrate. (C) 2002 Published by Elsevier Science Inc.
\end{abstract}

Keywords: Ketone body; In vitro; Culture; Bovine; Embryo

\footnotetext{
* Corresponding author. Tel.: +34-9851-95300; fax: +34-9851-95310.

E-mail address: enriqugp@princast.es (E. Gómez).

${ }^{1}$ Present address: Consejería de Agricultura, Cantabria, Spain.
} 


\section{Introduction}

In ruminants, mobilization of fat deposits in the animal causes elevated levels of ketone bodies in plasma, which are physiological markers of a negative energy balance. These compounds are quantitatively important as energy sources, since tissues such as heart and kidney cortex utilize acetoacetate in preference to glucose. Moreover, under particular circumstances like lactation and fasting, acetoacetate, D- $\beta$-hydroxybutyrate and the glycolytic compound lactate represent significant energy substrates for the brain. Similar to adult tissues, bovine embryos cultured in vitro develop up to the hatched blastocyst stage by using either acetoacetate or D- $\beta$-hydroxybutyrate [1], which can be derived from either endogenous (embryonic) or exogenous (female tract) sources, or both. Acetoacetate and D$\beta$-hydroxybutyrate may be utilized in aerobic metabolism, and their ratio is regulated dependently on the NADH:NAD ratio in the mitochondria. Maximal blood levels in healthy cows are $0.48 \mathrm{mM}$ for acetoacetate and $0.85 \mathrm{mM}$ for $\mathrm{D}-\beta$-hydroxybutyrate [2]. However, a mean level over $1.0 \mathrm{mM}$ for both ketones [3] or for $\mathrm{D}-\beta$-hydroxybutyrate alone $[4,5]$ is considered, in practice, to be the top limit of normality in the cow. This value is below the concentration required to sustain bovine embryo development in vitro [1].

The high lipid content of bovine embryos produced in vitro [6,7] seems to be represented mainly by triglycerides $[7,8]$. These lipids interfere with the ability of the embryo to survive cryopreservation, as demonstrated following mechanical delipidation [9-12]. Consumption of acetoacetate and D- $\beta$-hydroxybutyrate by IVP bovine embryos may be a means by which their lipid stocks could be degraded. At concentrations of $3.6 \mathrm{mM}$, these ketone bodies can act as primary energy sources at any time during in vitro development [13]. In experiments, embryos developed in synthetic oviduct fluid as modified by Takahashi and First (mSOF) [14] and was supplemented with serum. As an undefined compound, serum may give unrepeatable results. Although this problem can be overcome by using simple media under defined conditions, protein supplementation has been shown to be beneficial for embryo development in vitro [15]. Therefore, we have chosen a medium with albumin instead of with synthetic polymers to test the effects of acetoacetate in serum free culture conditions. During our preliminary experiments in mSOF containing albumin and no serum, acetoacetate seemed unable to support blastocyst development. As a consequence, the present work analyzes the effect of acetoacetate derivatives in the absence of serum, the requirement for serum in medium containing acetoacetate, the embryotrophic ability of D- $\beta$-hydroxybutyrate in the absence of serum and the lipid content of embryonic cells.

\section{Materials and methods}

Embryos for in vitro experiments derived from slaughterhouse ovaries, while blastocysts transferred to recipients derived from healthy cows by oocyte puncture ultrasonography. Ovaries from Asturiana de los valles cows were placed in $0.9 \%$ (w/v) $\mathrm{NaCl}$ containing antibiotics (penicillin, $100 \mathrm{UI} / \mathrm{ml}$, Sigma PEN-NA 69-57-8, Madrid, Spain; and streptomycin sulfate, $100 \mathrm{mg} / \mathrm{ml}$, Sigma $\mathrm{S}-6501$ ) and maintained at $30-35^{\circ} \mathrm{C}$ until recovery of cumulus-oocyte complexes (COCs). Ovaries were washed twice in distilled water, and once in freshly prepared saline and antibiotics. The COCs were aspirated from follicles 2 to 
$8 \mathrm{~mm}$ in diameter through an 18-gauge needle and recovered into a 50-ml plastic test tube (Nunc, Roskilde, Denmark). Follicular fluid and COCs were placed in an embryo filter and rinsed with holding medium, consisting of $4.2 \mathrm{mM} \mathrm{NaHCO} 3$ containing TCM-199 (Invitrogen \#31100027, Barcelona, Spain) and 20 mM HEPES (Sigma, H-3375), to which $2 \mathrm{UI} / \mathrm{ml}$ heparin (Sigma H-3393) was added.

\subsection{In vitro maturation}

Oocytes enclosed in a compact cumulus with evenly granulated cytoplasm were selected for maturation. The COCs were washed three times in maturation medium, which consisted of Medium 199, $10 \%$ (v/v) fetal calf serum (FCS, F-4135, Sigma), pFSH (1 $\mu \mathrm{g} / \mathrm{ml}$, Sigma), LH $(5 \mu \mathrm{g} / \mathrm{ml}$, Sigma), $17 \beta$-estradiol ( $1 \mu \mathrm{g} / \mathrm{ml}$, Sigma) and cysteamine $100 \mu \mathrm{M}$ (Sigma, M9768) [16]. Maturation was accomplished by culturing approximately 50 COCs in $500 \mu 1$ maturation medium in four-well dishes (Nunc) at $39{ }^{\circ} \mathrm{C}$ in $5 \% \mathrm{CO}_{2}$ under air and high humidity for $23-24 \mathrm{~h}$.

\subsection{In vitro fertilization}

In vitro fertilization was carried out using a swim-up procedure similar to that previously reported by Parrish et al. [17]. Briefly, semen from one frozen straw from a single bull was thawed in a water bath and added to a polystyrene tube containing $1 \mathrm{ml}$ of pre-equilibrated Sperm-TALP. After 1-h of incubation, $700 \mu \mathrm{l}$ of the upper layer of the supernatant containing the motile spermatozoa was removed. The sperm suspension was centrifuged for $7 \mathrm{~min}$ at $700 \times g$ and the supernatant aspirated to leave a pellet approximately $100 \mu \mathrm{l}$ in volume. Sperm concentration was determined with a hemocytometer. After maturation, the COCs were washed three times in holding medium, once in fertilization medium, and then placed in four-well culture dishes containing pre-equilibrated fertilization medium (FertTALP) with heparin $(10 \mu \mathrm{g} / \mathrm{ml}$, Calbiochem, 375095, La Jolla, CA). Spermatozoa were then added to a concentration of $2 \times 10^{6} \mathrm{cells} / \mathrm{ml}$ in $500 \mu \mathrm{l}$ of medium per well containing 50-100 COCs. In vitro fertilization was accomplished by incubating oocytes and sperm cells together for $20 \mathrm{~h}$ at $39{ }^{\circ} \mathrm{C}$ with $5 \% \mathrm{CO}_{2}$ in air and high humidity.

\subsection{Preparation of acetoacetate}

Sodium acetoacetate was obtained by hydrolysis of ethyl acetoacetate (Sigma, A-8646) with equimolar $\mathrm{NaOH}$ solution. The resulting product was aliquoted and treated to eliminate water and ethanol by either lyophilization or by evaporation for $3 \mathrm{~h}$ at $35^{\circ} \mathrm{C}$ under laminar flow. Some aliquots were untreated (ethanol-containing acetoacetate). The sodium acetoacetate prepared in this manner was stored at $-20{ }^{\circ} \mathrm{C}$ until used in culture.

\subsection{In vitro embryo culture}

Fertilized oocytes were vortexed for $2 \mathrm{~min}$ in holding medium to separate cumulus cells, rapidly washed three times in holding medium and twice in the corresponding culture medium, prior to a 8-day period of culture. Embryo cultures were performed in $\mathrm{mSOF}$, 
containing $20 \mu \mathrm{l} / \mathrm{ml}$, essential amino acids (BME) (Sigma, B-6766), $10 \mu \mathrm{l} / \mathrm{ml}$, nonessential amino acids (MEM) (Sigma, M-7145) and $8 \mathrm{mg} / \mathrm{ml}$ BSA (Sigma, A-3311), to which FCS $(10 \% \mathrm{v} / \mathrm{v})$ was added, where indicated, $48 \mathrm{~h}$ post-insemination. In culture media containing acetoacetate or D- $\beta$-hydroxybutyrate (Sigma, H-0265), each of these compounds replaced lactate and pyruvate. Culture media were renewed on Days 3 and 6 of culture (fertilization: Day 0). Media were freshly prepared and had a pH of 7.2-7.3 and osmolality of 280$290 \mathrm{mOsm}$. A volume of $50 \mu \mathrm{l}$ droplets (1-2 $\mu \mathrm{l} / \mathrm{embryo}$, approximately) of the corresponding culture medium were prepared in four-well culture dishes under mineral oil and allowed to equilibrate in the incubator for at least $2 \mathrm{~h}$ before the addition of embryos. Embryo development was assessed at 48, 144, 168, 192, and $216 \mathrm{~h}$ of culture. Culture conditions were $39{ }^{\circ} \mathrm{C}$ and high humidity in $5 \% \mathrm{CO}_{2}$ in air. Some groups of Day-7 embryos were allowed to hatch by placing them in drops of $50 \mu \mathrm{l}$ of Upgraded B2 INRA Medium (B2) (C.C.D., Paris, France) supplemented with 10\% FCS, seeded with vero cells and overlaid with mineral oil.

\subsection{Experimental design}

For in vitro cultures, experiments were performed as follows:

Experiment 1 analyzed the effect of the presence of serum on in vitro development of embryos cultured in medium containing acetoacetate.

Experiment 2 tested the embryotrophic effects of acetoacetate or D- $\beta$-hydroxybutyrate present at post-compaction development (Days 6-8) in the absence of serum. Analyses include expansion development, blastocyst quality by cell counts, and capacity of embryos from selected groups (D- $\beta$-hydroxybutyrate and lactate + pyruvate) to hatch in a feeder cell coculture.

Experiment 3 tested the embryonic development in the presence of D- $\beta$-hydroxybutyrate and lactate + pyruvate at pre-compaction period (Days 0-6) in the absence of serum.

\subsection{Cell counts}

Blastocysts were maintained for $20 \mathrm{~min}$ in hypotonic solution $(0.9 \% \mathrm{w} / \mathrm{v}$ sodium citrate in double-distilled water), fixed with methanol, acetic acid and double-distilled water $(3: 2: 1, \mathrm{v} / \mathrm{v} / \mathrm{v})$, and stained with Giemsa (1:20, v/v in double-distilled water) for $15 \mathrm{~min}$. Cell counts were carried out at $200 \times$ under a light microscope.

\subsection{Light microscopy study}

Control morulae, and fully expanded blastocysts from Groups lactate and pyruvate, No substrate and D- $\beta$-hydroxybutyrate (Experiment 2 ) were fixed for microscopy in $2 \%$ glutaraldehyde (Fluka Chemie, Buchs, Germany) in 0.1 M Sörensen phosphate buffer ( $\mathrm{pH}$ 7.4), post-fixed in $1 \%$ buffered $\mathrm{OsO}_{4}$ for $15 \mathrm{~min}$ and dehydrated in graded ethanol. Embryos were embedded in Unicryl resin (British BioCell, Cardiff, UK). After embedding, the specimens were placed in capsules containing fresh resin, which were allowed to polymerize at $60{ }^{\circ} \mathrm{C}$ for $48 \mathrm{~h}$. Semi-thin sections $(1-2 \mu \mathrm{m})$ were cut with an ultramicrotome 
equipped with a Histo diamond knife (Diatome, Bienne, Switzerland), and stained with $0.2 \%$ toluidine blue with $2 \%$ borax. Finally, embryos were photographed with a DP-11 digital camera (Olympus, Tokyo, Japan) attached to an Orthoplan microscope (Leitz, Wetzlar, Germany).

\subsection{Embryo transfer}

Morulae produced in medium with lactate and pyruvate were cultured from Day 6 up to Day 7.5 in medium containing D- $\beta$-hydroxybutyrate. At this time, blastocysts were selected according to their morphological appearance and nonsurgically transferred to synchronized recipients. Recipient heifers $(n=4)$ received one embryo each, while recipient cows $(n=4)$ received two embryos each. All embryos were transferred to the uterine horn adjacent to a corpus luteum. Pregnancy diagnosis was established by plasma progesterone determination on Day 21, bovine Pregnancy-Specific Protein B (bPSPB) [18] on Day 30 and ultrasonographic scanning after Day 50.

\subsection{Statistical analysis}

Data were analyzed by ANOVA. The numbers of replicates and treatments were considered as fixed effects. The Duncan's test or the REGWF test for the different variables were used, where indicated, to estimate the significance of mean values. Data were expressed as mean percentages \pm S.E.M. of the corresponding elements.

\section{Results}

During the experiments 3085 oocytes were processed. The types of acetoacetate tested in our preliminary study (lyophilized, evaporated or untreated) were unable to support morula and blastocyst development as replacement for lactate and pyruvate in mSOF with $8 \mathrm{~g} / \mathrm{l}$ BSA. Since the compound employed in previous embryo culture in the presence of serum was lyophilized acetoacetate and no other [13], this was the product used in the experiments.

In Experiment 1 (Table 1), development of embryos cultured in acetoacetate in the absence of serum was lower as early as the morula stage. However, serum did not exert similar effect in the presence of lactate and pyruvate or in the absence of substrates.

Results of Experiment 2 can be seen in Tables 2 and 3. Out of 516 Day 6 morulae and early blastocysts, $11 \%$ were judged as being early blastocysts. D- $\beta$-hydroxybutyrate significantly stimulated Day 7 and Day 8 blastocyst development, but D- $\beta$-hydroxybutyrate had no effect on expansion. Nevertheless, hatching rate improved when Day 7 , D- $\beta$ hydroxybutyrate-produced embryos were developed in medium B2 containing vero cells. Interestingly, lactate and pyruvate, and acetoacetate were unnecessary for embryos to progress to later stages. No differences were found between number of cells of expanded blastocysts from any group counted.

In Experiment 3 (Table 4), D- $\beta$-hydroxybutyrate promoted higher proportions of expansion when D- $\beta$-hydroxybutyrate-produced embryos were cultured from Day 6 in 
Table 1

Effect of the presence of serum on in vitro development of bovine embryos cultured in medium containing acetoacetate

\begin{tabular}{llllrll}
\hline Energy substrates & FCS & $n$ & \% Cleaved & \% Morulae & \multicolumn{2}{l}{ \% Blastocysts } \\
\cline { 5 - 7 } & & & & & Day 7 & Day 8 \\
\hline Lactate + pyruvate & + & 106 & $89.4 \pm 2.5$ & $36.6 \pm 2.9 \mathrm{a}$ & $22.4 \pm 3.6 \mathrm{a}$ & $22.4 \pm 3.6 \mathrm{a}$ \\
Lactate + pyruvate & - & 117 & $87.2 \pm 4.8$ & $34.0 \pm 2.9 \mathrm{a}$ & $14.5 \pm 5.6 \mathrm{abc}$ & $19.9 \pm 4.6 \mathrm{a}$ \\
Acetoacetate & + & 126 & $86.0 \pm 2.7$ & $29.6 \pm 2.7 \mathrm{a}$ & $16.8 \pm 1.6 \mathrm{ab}$ & $18.1 \pm 2.4 \mathrm{a}$ \\
Acetoacetate & - & 127 & $89.1 \pm 0.9$ & $9.9 \pm 2.7 \mathrm{~b}$ & $3.3 \pm 2.0 \mathrm{c}$ & $4.2 \pm 1.8 \mathrm{~b}$ \\
No substrate & + & 74 & $82.1 \pm 2.3$ & $24.9 \pm 8.0 \mathrm{a}$ & $9.2 \pm 5.0 \mathrm{bc}$ & $9.3 \pm 5.0 \mathrm{bc}$ \\
No substrate & - & 96 & $84.4 \pm 2.3$ & $27.5 \pm 5.5 \mathrm{a}$ & $5.0 \pm 3.1 \mathrm{c}$ & $7.2 \pm 2.7 \mathrm{~b}$ \\
\hline
\end{tabular}

Data from four replicates; $n$ : number of oocytes; different letters $(\mathrm{a}, \mathrm{b}, \mathrm{c})$ within columns differ significantly $(P<0.05)$. ANOVA and REGWF test.

Table 2

Effect of acetoacetate and D- $\beta$-hydroxybutyrate in the absence of FCS upon embryo development, starting from Day 6 morulae and early blastocysts produced in mSOF with $8 \mathrm{~g} / \mathrm{l} \mathrm{BSA}$ containing lactate and pyruvate

\begin{tabular}{llrlll}
\hline Energy substrates & $R$ & \multicolumn{1}{c}{$n$} & \% Blastocysts (Day 7) & \% Expanded blastocysts (Day 8) & Number of cells \\
\hline D- $\beta$-Hydroxybutyrate & 6 & 104 & $53.7 \pm 6.5 \mathrm{a}$ & $36.3 \pm 8.5$ & $82.2 \pm 6.3$ \\
Acetoacetate & 5 & 82 & $37.8 \pm 8.2$ & $24.8 \pm 10.2$ & $79.9 \pm 7.7$ \\
Lactate + pyruvate & 6 & 102 & $37.4 \pm 4.8 \mathrm{~b}$ & $29.0 \pm 6.9$ & $70.0 \pm 6.7$ \\
No substrate & 6 & 99 & $33.9 \pm 6.6 \mathrm{~b}$ & $32.2 \pm 5.4$ & $75.0 \pm 6.1$ \\
\hline
\end{tabular}

$R$ : number of replicates; $n$ : number of Day 6 morulae and early blastocysts; different letters $(\mathrm{a}, \mathrm{b})$ within columns differ significantly $(P<0.05)$. ANOVA and Duncan's test.

Table 3

Effect of D- $\beta$-hydroxybutyrate and lactate and pyruvate in culture after $30 \pm 2 \mathrm{~h}$ on development of Day 6 bovine embryos produced in mSOF with $8 \mathrm{~g} / \mathrm{l} \mathrm{BSA}$ containing lactate and pyruvate

\begin{tabular}{llllll}
\hline Energy substrates & \multirow{2}{*}{ \% } & \% Blastocysts (Day 8) & \multicolumn{2}{l}{$\%$ Hatched blastocysts } \\
\cline { 4 - 6 } & & & Day 8 & Day 9 & Day 10 \\
\hline D- $\beta$-Hydroxybutyrate & 65 & $77.7 \pm 4.4 \mathrm{a}$ & $20.8 \pm 4.8 \mathrm{a}$ & $47.8 \pm 10.5$ & $49.5 \pm 13.1$ \\
Lactate + pyruvate & 64 & $52.8 \pm 6.8 \mathrm{~b}$ & $8.6 \pm 2.3 \mathrm{~b}$ & $30.7 \pm 5.9$ & $29.8 \pm 6.6$ \\
\hline
\end{tabular}

Subsequent development took place in Medium B2 and vero cells. Data from four replicates; $n$ : number of Day 6 morulae and early blastocysts; different letters $(\mathrm{a}, \mathrm{b})$ within columns differ significantly $(P<0.05)$. ANOVA and Duncan's test.

Table 4

Bovine embryo development in the presence of $D-\beta$-hydroxybutyrate and lactate and pyruvate at precompaction period (Days 0-6) in the absence of serum

\begin{tabular}{|c|c|c|c|c|c|}
\hline \multirow[t]{2}{*}{ Treatment from Days 0-6 } & \multirow[t]{2}{*}{$n$} & \multicolumn{2}{|l|}{$\%$ Blastocysts } & \multicolumn{2}{|c|}{$\%$ Expanded blastocysts } \\
\hline & & Day 7 & Day 8 & Day 7 & Day 8 \\
\hline Lactate + pyruvate & 62 & $41.0 \pm 11.3$ & $45.4 \pm 9.0$ & $14.6 \pm 7.1 \mathrm{a}$ & $22.3 \pm 9.4$ \\
\hline D- $\beta$-Hydroxybutyrate & 49 & $49.7 \pm 11.3$ & $52.3 \pm 12.2$ & $21.6 \pm 9.4 b$ & $26.9 \pm 10.0$ \\
\hline
\end{tabular}

Data from four replicates; $n$ : number of morulae and early blastocysts; different letters $(\mathrm{a}, \mathrm{b})$ within columns differ significantly $(P<0.05)$. ANOVA and Duncan's test. 
comparison to their Day 6 lactate and pyruvate-produced counterparts. Morulae and early blastocysts represented 42 and $36 \%$ of the cultured oocytes for lactate and pyruvate, and D$\beta$-hydroxybutyrate, respectively.

\subsection{Light microscopy}

At the light microscope level, morulae showed a high number of intracytoplasmic lipid droplets (Fig. 1) which seem to be consumed when embryos develop to the expanded blastocyst stage. The Day 7 fully expanded blastocysts developed from Day 6 in the absence of lactate and pyruvate (Fig. 1b), or in D- $\beta$-hydroxybutyrate (Fig. 1c) showed fewer intracytoplasmic lipid droplets than embryos developed in lactate and pyruvate (Fig. 1d).

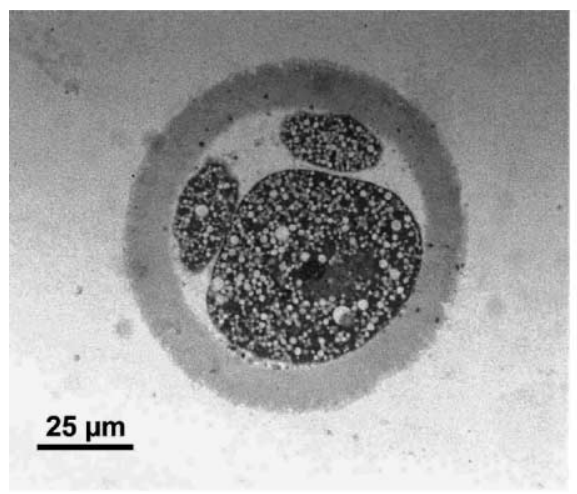

(a)

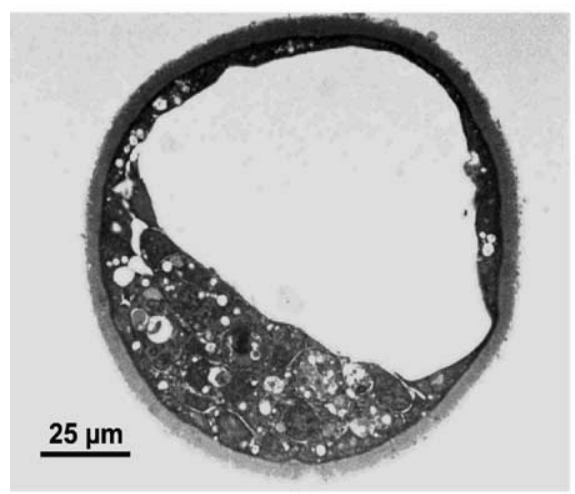

(c)

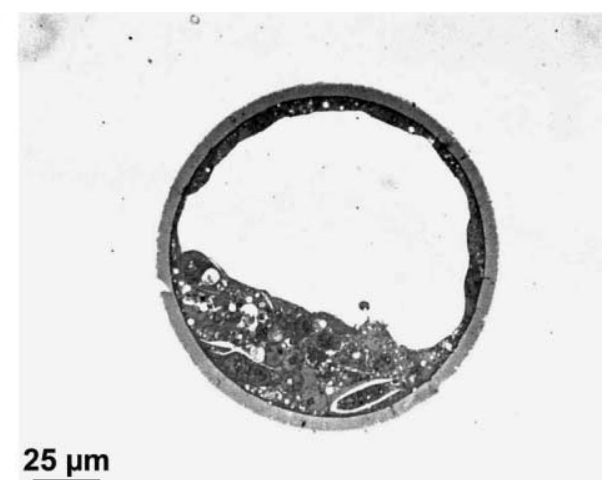

(b)

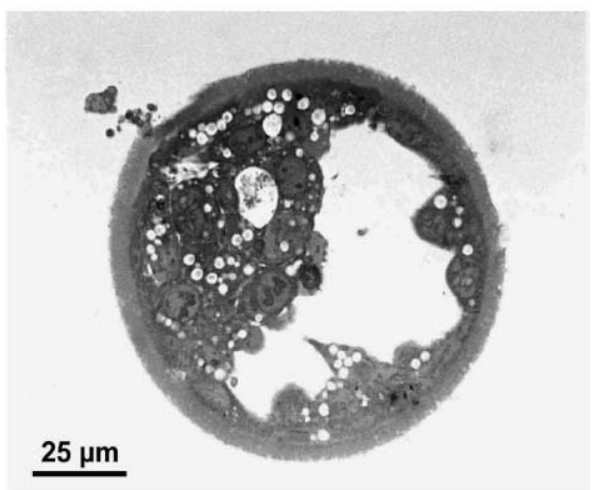

(d)

Fig. 1. (a) Day 6 morula (note a high number of lipid microdroplets, stain: $0.2 \%$ toluidine blue $+2 \%$ borax); (b) fully expanded blastocyst cultured from Day 6 in SOF without L/P (stain: $0.2 \%$ toluidine blue $+2 \%$ borax); (c) fully expanded blastocyst cultured from Day 6 in SOF + D- $\beta$-hydroxybutyrate (staining: $0.2 \%$ toluidine blue $+2 \%$ borax); (d) fully expanded blastocyst cultured from Day 6 in SOF + L/P (staining: $0.2 \%$ toluidine blue $+2 \%$ borax). 


\subsection{Embryo transfer}

All recipient cows (two embryos each) and two of four recipient heifers (one embryo each) showed Day 21 progesterone values $>4 \mathrm{ng} / \mathrm{ml}$, and no signs of estrus were observed. The remaining two recipient heifers showed standing estrus and progesterone values $<2 \mathrm{ng} / \mathrm{ml}$. In recipient heifers, PSPB measurements on Day 30 were less than $0.5 \mathrm{ng} / \mathrm{ml}$. Although any recipient assumed to be pregnant on Day 21 (progesterone $>4 \mathrm{ng} / \mathrm{ml}$ ) was observed in estrus, all recipients were diagnosed as open at ultrasonographic scanning after Day 50.

\section{Discussion}

Fetal calf serum allowed acetoacetate to show embryotrophic effect during the entire culture period, making it difficult to understand the role of this compound during early bovine embryo development in vitro. A recent work run in parallel yielded similar results in SOF medium containing citrate and myo-inositol, and proved the purity of the acetoacetate preparation used in these experiments [19]. The need for serum in an embryo culture represents an additional problem, and endorses the need for re-formulation of classical culture media to be used in completely defined conditions [20,21]. To our knowledge, no explanation about the protective effect of serum upon acetoacetate exists. A possible mechanism could be the incorporation of acetoacetate into embryonic lipid, circumventing in part the direct metabolization of acetoacetate. Oleic acid incorporated from culture media by bovine embryos produced in vitro in serum-containing medium accounted for $58.4 \%$ of embryonal triglyceride [8]. It is well-documented that the presence of serum in culture media leads to excessive synthesis or accumulation of lipids in early bovine embryos [6,7].

Elevated levels of acetoacetate can generate oxygen radicals and cause lipid peroxidation in human endothelial cells. Using cell-free buffered solution, acetoacetate, but not D- $\beta$-hydroxybutyrate, showed a significant superoxide dismutase inhibitable reduction of cytochrome $\mathrm{C}$, suggesting the generation of superoxide anion radicals by acetoacetate [22]. This possibility may have been enhanced in our experiments by the fact that oxygen concentration was not reduced to 5-10\%; an experiment we intend to perform in the future. The ineffectiveness of acetoacetate in the absence of serum was also demonstrated during shorter culture periods (i.e. from Days 6 to 8), as was that of lactate and pyruvate. However, medium containing D- $\beta$-hydroxybutyrate exhibited improved blastocyst hatching development, suggesting a better quality of these embryos. This is in contrast with previous reports where $\mathrm{D}-\beta$-hydroxybutyrate in the presence of serum did not exert any stimulating effect on development from Days 6 to 8 [13]. When cultured in medium containing D- $\beta$-hydroxybutyrate up to Day 8 , the percentage of expansion of Day 6 embryos produced in the presence of this substrate was superior to that of Day 6 lactate and pyruvate-produced embryos. However, although D- $\beta$-hydroxybutyrate from Days 0 to 6 did not significantly reduce yields of Day 6 morulae and early blastocysts, more research is needed to determine the precise timing of $\mathrm{D}$ - $\beta$-hydroxybutyrate in embryo culture. Ketone bodies might be associated with other factors that are not involved in energy metabolism, i.e. the 
interconversion of $\mathrm{D}$ - $\beta$-hydroxybutyrate and acetoacetate as a means of controlling intracellular $\mathrm{pH}$.

Lactate and pyruvate, which are the energy substrates normally contained in SOF, did not exert any effects at the post-compaction period. This concurs with a previously reported role for these compounds as preferred energy substrates during the cleavage stages [23]. Day 6 embryos can normally develop by using other compounds present in the culture medium as energy substrates, e.g. amino acids or glutamine [23] and albumin [14]. The type of, or presence of substrate in the culture medium did not affect the number of cells of expanded blastocysts produced in the absence of serum from Days 6 to 8 .

In a previous study, the lyophilized and untreated (ethanol-containing) acetoacetate derivatives were shown to support bovine embryo development in vitro in the presence of serum [1]. Lyophilization is a time consuming operation which we thought could be replaced by the shorter evaporation procedure, yielding a product as yet untested in culture. However, in the present work all acetoacetate derivatives were shown to be incapable of providing developmental support in the absence of serum. The ethanol-containing acetoacetate exhibited a propensity for toxicity which should be examined in further experiments.

The role of ketone bodies in embryo development in mammals is widely unexplored. In particular, in ruminants, the metabolic role of $\mathrm{D}$ - $\beta$-hydroxybutyrate seems to be generally less than that of the reduced derivative butyrate, possibly due to its association with other quantitatively important short-chain fatty acids such as acetate and propionate [24]. Interestingly, sodium butyrate was demonstrated to improve the ability of murine embryos to hatch in culture after incubation in a solution at $4{ }^{\circ} \mathrm{C}$ [25]. In lactating cows, elevated levels of ketone bodies in plasma are indicative of lipid breakdown, and free nonesterified fatty acids are needed to produce ketones from fat [26,27]. In order to be oxidized, fatty acids must first enter the mitochondria, thereby, generating ketone bodies, which can be readily metabolized, or diffuse to and be used in other organs. To summarize, embryos may utilize exogenous ketones [1,13], exogenous fatty acids [8,28,29] and endogenous lipids [13]. Intracytoplasmic lipid disappearance could be indicative of lipid consumption promoted by the absence of substrates. In oviducal fluid, a variety of lipids have been reported in the bovine [28,30,31] and the rabbit oviduct may convert propionate to pyruvate [32]. Nevertheless, the beneficial effects of lipids in bovine embryo culture are yet to be demonstrated.

Embryos produced in the presence of D- $\beta$-hydroxybutyrate after Day 6 were viable upon transfer, although no pregnancies were later verified by ultrasonic scanning. In our experimental herd, births of calves from single and double transfer of IVP embryos grown in vero cell-cocultures are within acceptable rates (30-40\%). However, Massip et al. [33] suggested the inability of embryos produced in SOF with high $\mathrm{O}_{2}$ concentration to establish pregnancies, in contrast with embryos produced with $5 \% \mathrm{O}_{2}$. These embryos present developmental capacity comparable to embryos from other systems. It is interesting to note that most of our embryonic losses occurred after Day 21 (six out of eight recipients), while Massip et al. [33] reported only $11 \%$ pregnancies at this stage (oneninth). Blastocysts cultured from Day 6 up to hatching in the presence of D- $\beta$-hydroxybutyrate clearly showed necrosis and cellular degeneration which could explain failure to maintain pregnancies. Therefore, whether either $21 \% \mathrm{O}_{2}$ or D- $\beta$-hydroxybutyrate itself, or both, were responsible for pregnancy failure needs to be investigated. 
The fact that the bovine embryo is able to develop in a concentration of ketones higher than the physiological limit in the cow $(1.0 \mathrm{mM})$ might represent an ability to survive under conditions of nutrient starvation (i.e. fasting or during the early lactation period) or embryonic lipid breakdown. The evidence provided here, that the use of the ketone body D$\beta$-hydroxybutyrate is more efficient at the morula and blastocyst stages of development, corresponds to the greater importance of oxidative metabolism and mitochondria at these stages [34]. An embryonic source of ketone bodies could partly explain the shift from oxidative phosphorylation towards glycolysis at the time of compaction when glucose is available [14,35-37], despite increased oxygen consumption. Ketone bodies generated from embryonic stocks might harness the oxidative capacity of the cells to a higher extent than lactate. In recent studies, bovine blastocyst development was stimulated when oxidative phosphorylation was partially uncoupled with 2,4-dinitrophenol in the presence of glucose, sodium azide or low oxygen tension [38], but was arrested when inhibited with cyanide [39]. The cyanide toxicity could be due to its dosage in excess, although the absence of glucose in a culture medium containing only oxidizable substrates could be the determining factor. This supports the role of oxidizable substrates at these developmental stages.

In conclusion, fetal calf serum prevents the toxic effect of acetoacetate during early bovine embryo development in vitro. This provides encouragement to investigate this phenomenon further and to design appropriate culture media to study the effects of acetoacetate in the absence of serum. In addition, D- $\beta$-hydroxybutyrate improves embryo development in vitro under serum free conditions and is a candidate for testing under completely defined conditions.

\section{Acknowledgements}

The authors thank Dr. P. Booth for criticism and translation, L. Prieto, I. Fernández and J.M. Prendes for help. This work was supported by a grant from FEDER, project 1FED970023.

\section{References}

[1] Gómez E. Acetoacetate and $\beta$-D-hydroxybutyrate as energy substrates during early bovine embryo development in vitro. Theriogenology 1997;48:63-74.

[2] Courcel B. Constantes biochimiques sanguines de la vache laitiere (these). Maisons-Alfort, France. Publications de l'Ecole Nationale Veterinaire, 1972. p. 48-52.

[3] Jonker LJ, Wilkinson JID, Tarrant M. Alleviated nutrient imbalance by monensin premix (Romensin R, Rumensin R); reduced risk of ketonaemia in dairy cows. Bovine Pract 1998;32:31-3.

[4] Duffield TF, Sandals D, Leslie KE, Lissemore K, McBride BW, Lumsden JH, Dick P, Bagg R. Efficacy of monensin for the prevention of subclinical ketosis in lactating dairy cows. J Dairy Sci 1998;81:2866-73.

[5] Kristensen NB, Danfaer A, Agergaard N. Absorption of short-chain fatty acids in ruminants. Arch Tierernahr 1998;51:2-3.

[6] Abe H, Yamashita S, Itoh T, Satoh T, Hoshi H. Ultrastructure of bovine embryos developed from in vitro matured and fertilized oocytes: comparative morphological evaluation of embryos cultured either in serum-free medium or in serum-supplemented medium. Mol Reprod Dev 1999;53:325-35. 
[7] Ferguson EM, Leese HJ. Triglyceride content of bovine oocytes and early embryos. J Reprod Fertil 1999;116:373-8.

[8] Abd El Razek IM, Charpigny G, Kodja S, Marquant-Leguienne B, Mermillod P, Guyader-Joly C, et al. Differences in lipid composition between in vivo- and in vitro-produced embryos. Theriogenology 2000;53:346. [Abstract].

[9] Diez C, Heyman Y, Le Bourhis D, Guyader-Joly C, Renard JP. Delipidation of in vitro-produced bovine zygotes: effect on further development and consequences for freezability. Theriogenology 2001;55:92336.

[10] Leibo SP, Pollard JW, Martino A. Chilling and freezing sensitivity of "reassembled" in vitro-derived bovine embryos. Theriogenology 1995;43:265 [Abstract].

[11] Ushijima H, Yamakawa H, Nagashima H. Cryopreservation of bovine IVM/IVF embryos at early cleavage stage following removal of cytoplasmic lipid droplets. Theriogenology 1996;45:159. [Abstract].

[12] Ushijima H, Yamakawa H, Hagashima H. Cryopreservation of bovine premorula-stage in vitro matured/in vitro fertilized embryos after delipidation and before use in nucleus transfer. Biol Reprod 1999;60:534-9.

[13] Gómez E, Díez C. Use of ketone bodies as energy substrates at different developmental stages and under different oxygen tensions by bovine embryos produced in vitro. Arch Zootec 1999;48:207-17.

[14] Takahashi Y, First NL. In vitro development of bovine one-cell embryos: influence of glucose, lactate, pyruvate and vitamins. Theriogenology 1992;37:963-78.

[15] Gomez E, Diez C. Effects of glucose and protein sources on bovine embryo development in vitro. Anim Reprod Sci 2000;58:23-37.

[16] De Matos DG, Furnus CC, Moses DF, Baldassarre H. Effect of cysteamine on glutathione level and developmental capacity of bovine oocyte matured in vitro. Mol Reprod Dev 1995;42:432-6.

[17] Parrish JJ, Susko-Parrish JL, Leibfried-Ruthledge ML, Critser ES, Eyestone WH, First NL. Bovine in vitro fertilization with frozen-thawed semen. Theriogenology 1986;25:591-600.

[18] Humblot P, Camous S, Martal J, Charlery J, Jeanguyot N, Thibier M, et al. Pregnancy specific protein b, progesterone concentrations and embryonic mortality during early pregnancy in dairy cows. J Reprod Fertil 1988;83:215-23.

[19] Gómez E, Duque P, Díaz E, Díez C. Effects of acetoacetate on in vitro development of bovine embryos in medium containing citrate and myo-inositol. Reprod Dom Anim 2001;36:1-6.

[20] Rieger D, Guay P. Measurement of the metabolism of energy substrates in individual bovine blastocysts. J Reprod Fertil 1988;83:585-91.

[21] Rieger D, Loskutoff NM, Betteridge KJ. Developmentally related changes in the metabolism of glucose and glutamine by cattle embryos produced and cocultured in vitro. J Reprod Fertil 1992;195:585-95.

[22] Jain SK, Kannan K, Lim G. Ketosis (acetoacetate) can generate oxygen radicals and cause increased lipid peroxidation and growth inhibition in human endothelial cells. Free Radic Biol Med 1998;25:1083-8.

[23] Gardner DK. Changes in requirements and utilization of nutrients during mammalian preimplantation embryo development and their significance in embryo culture. Theriogenology 1998;49:83-102.

[24] Killian GJ, Chapman DA, Kavanaugh JF, Deaver DR, Wiggin HB. Changes in phospholipids, cholesterol and protein content of oviductal fluid of cows during the oestrous cycle. J Reprod Fertil 1989;86: 419-26.

[25] Wiggins PM, Rowlandson J, Ferguson AB. Preservation of murine embryos in a state of dormancy at $4{ }^{\circ} \mathrm{C}$. Am J Physiol 1999;276:291-9.

[26] Roh S, Park JI, Shin TY, Lee BC, Hwang WS. The effect of sodium chloride concentration in chemically defined medium on development of bovine embryos in vitro. Theriogenology 1999;51:252. [Abstract].

[27] Rukkwamsuk T, Wensing T, Kruip TAM. Relationship between triacilglycerol concentration in the liver and first ovulation in postpartum dairy cows. Theriogenology 1999;51:1133-42.

[28] Kane MT, In vitro growth of preimplantation rabbit embryos. In: Bavister BD, editor. The mammalian preimplantation embryo. New York: Plenum, 1987. p. 193-217.

[29] Hewitson LC, Martin KL, Leese HJ. Effects of metabolic inhibitors on mouse preimplantation embryo development and the energy metabolism of isolated inner cell masses. Mol Reprod Dev 1996;43:323-30.

[30] Henault MA, Killian GJ. Synthesis and secretion of lipids by bovine oviductal mucosal explants. J Reprod Fertil 1993a;98:431-8.

[31] Henault MA, Killian GJ. Neutral lipid droplets in bovine oviductal epithelium and lipid composition of epithelial cell homogenates. J Dairy Sci 1993;76:691-700. 
[32] Leese HJ. The stimulation of pyruvate appearance in the rabbit oviduct by sodium proprionate. J Reprod Fertil 1980;59:421-4.

[33] Massip A, Mermillod P, Van Langendonckt A, Reichenbach HD, Lonergan P, Berg U, et al. Calving outcome following transfer of embryos produced in vitro in different conditions. Anim Reprod Sci 1996;44:1-10.

[34] Barnett DK, Bavister BD. What is the relationship between the metabolism of preimplantation embryos and their development in vitro? Mol Reprod Dev 1996;43:105-33.

[35] Sato H, Matsumoto M, Hanasaka S. Relations between plasma acetate, 3-hydroxybutyrate, FFA, glucose levels and energy nutrition in lactating dairy cows. J Vet Med Sci 1999;61:447-51.

[36] Thompson JG, Cox S, McGowan LT, Tervit HR. Development and metabolic activity of bovine in vitroproduced blastocysts cultured in the presence of 2,4-dinitrophenol during compaction and blastulation. Theriogenology 2000;53:303. [Abstract].

[37] Waugh EE, Wales RG. Oxidative utilization of glucose, acetate and lactate by early preimplantation sheep, mouse and cattle. Reprod Fertil Dev 1993;5:123-33.

[38] Thompson JG, Sherman AN, Allen NW, McGowan LT, Tervit HR. Total protein synthesis within preelongation stage bovine embryos. Mol Reprod Dev 1998;50:139-45.

[39] Donnay I, Bernard S, Feugang JM, Kaidi S, Moens A. Effect of cyanide (KCN) on bovine embryo development and apoptosis. Theriogenology 2000;53:350. [Abstract]. 